\title{
ULTRASOUND SKILLS IN LOWER EXTREMITY TRAUMATOLOGY AND ORTHOPEDICS - REGIONAL ANESTHESIA AND BEYOND
}

\author{
Krešimir Oremuš
}

AKROMION Special Hospital for Orthopedic Surgery, Krapinske Toplice

\begin{abstract}
SUMMARY - During the last two decades ultrasound guidance has been established as an invaluable tool for performing peripheral nerve blocks. Ultrasound guidance reduces block performance time, volume of local anesthetic, risk of intravascular injection and need for opioid rescue analgesia compared to landmark based and neurostimulator guided techniques. The use of ultrasound guidance must not be understood as a surrogate to, but should complement a thorough understanding of anatomy. The purpose of this overview is to present ultrasound guided techniques for performing basic lower extremity blocks, as well as to discuss more recent trends in providing regional analgesia for patients undergoing lower extremity surgery.
\end{abstract}

Key words: regional anesthesia, ultrasound, lower extremity

\section{Introduction}

During the last two decades ultrasound guidance has become an invaluable tool in performing lower extremity nerve blocks. The introduction of ultrasound has led to a reduction in block performance and onset time, volume of local anesthetic necessary to produce a successful block and has decreased the risk of accidental intravascular injection compared to traditional surface anatomy landmark and neurostimulator guided techniques ${ }^{1}$. However, the use of ultrasound guidance must not be understood as a surrogate for a thorough knowledge of regional anatomy. An all too common mistake is to use ultrasound for "pattern recognition" and treating block performance as finding "targets" on the screen disregarding the surrounding structures. U1trasound imaging should be used to supplement classical textbook anatomy knowledge and gain a deeper understanding of the anatomy of neural structures and

Correspondence to: prim. Krešimir Oremuš, AKROMION Special Hospital for Orthopedic Surgery, Ljudevita Gaja 2, 49210 Krapinske Toplice

E-mail: kresimir.oremus@akromion.hr how they relate to surrounding tissues in real time during block performance. It also helps us to appreciate variations in anatomy, which more often than not are the norm and not exception ${ }^{2}$.

Lower extremity innervation is derived from the lumbar (anterior divisions of L1, L2, L3 and part of L4 spinal nerves) and sacral (L4, L5, S1, S2 and S3 spinal nerves) plexus. The lumbar plexus gives rise to three major terminal nerves important for lower extremity anesthesia - femoral, obturator and lateral cutaneous nerve of the thigh. After its origin it lies anterior to the lumbar transverse processes and all of its branches run within the psoas muscle. The individual nerves, after emerging from the psoas muscle, leave the pelvic region by passing under the inguinal ligament. The sacral plexus transverses the sciatic foramen by passing anterior to the pelvic fascia and in front of or sometimes running (in part) through the piriformis muscle. After giving of direct branches for the posterior pelvic/gluteal musculature and sensory branches for the hip joint, its two terminal branches - the posterior cutaneous nerve of the thigh and sciatic nerve - descend to the posterior thigh running in between the sciatic tuberosity and greater trochanter posterior to the qua- 
dratus femoris muscle. In contrast to the upper extremity, anesthesia of the entire lower extremity cannot be achieved by a single injection. The aim of this overview is to present the ultrasonographic anatomy relevant to lower extremity regional anesthesia/analgesia. Besides the classical techniques, in which ultrasound is used to position the needle tip in close proximity to individual nerves, the role of ultrasound guidance in fascial plane blocks of the lower extremity will be discussed.

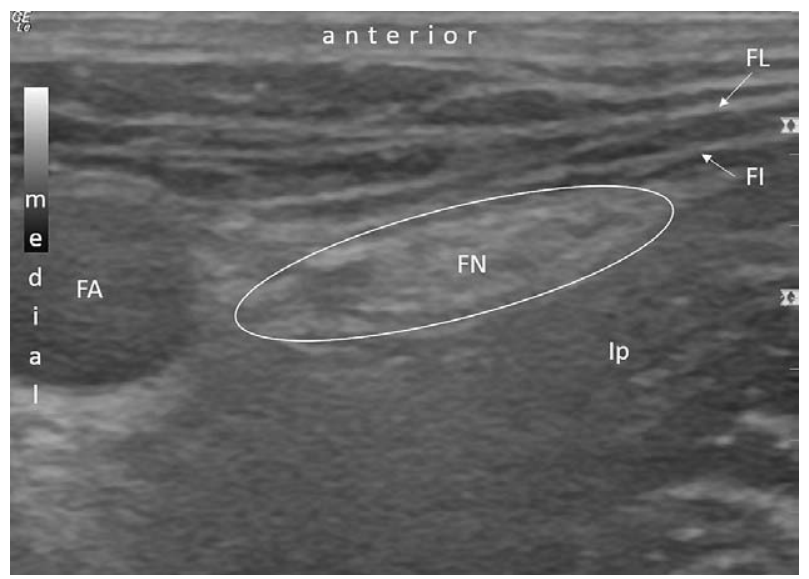

Figure 1. Femoral nerve in inguinal region.

FN - femoral nerve; FA - femoral artery; Ip - Ileopsoas muscle; FL - fascia lata; FI - iliac fascia

\section{Femoral nerve block and the femoral triangle}

The femoral nerve (L2, L3, L4) is the largest branch of the lumbar plexus and it enters the thigh passing bellow the inguinal ligament which forms the base of the femoral triangle. The femoral triangle is a triangular region distal to the inguinal ligament whose medial border is the medial border of the adductor longus muscle, laterally it is bound by the sartorious muscle. Its floor is formed by the pectineus and adductor longus muscles medially and iliopsoas muscle laterally. In the proximal part the roof of the femoral triangle is formed by the fascia lata and distally by the belly of the sartorious muscle. Some traditional definitions of the femoral triangle have put its apex at the intersection of the medial border sartorious and the lateral border of the adductor longus. However, a more functional approach is to view its apex as being the intersection between the medial margins of the sartorius and medial border of the adductor longus muscles marking the entrance to the adductor canal ${ }^{3}$. The femoral nerve is easily visualized by ultrasound as a hyperechoic region, roughly triangular in shape as it emerges bellow the inguinal ligament into the upper thigh covered by the fascia lata and iliac fascia, the latter separating it from the femoral vessels. It always lies lateral to the femoral artery and on the iliopsoas muscle (fig.1). Femoral nerve block produces anesthesia of the anterior thigh

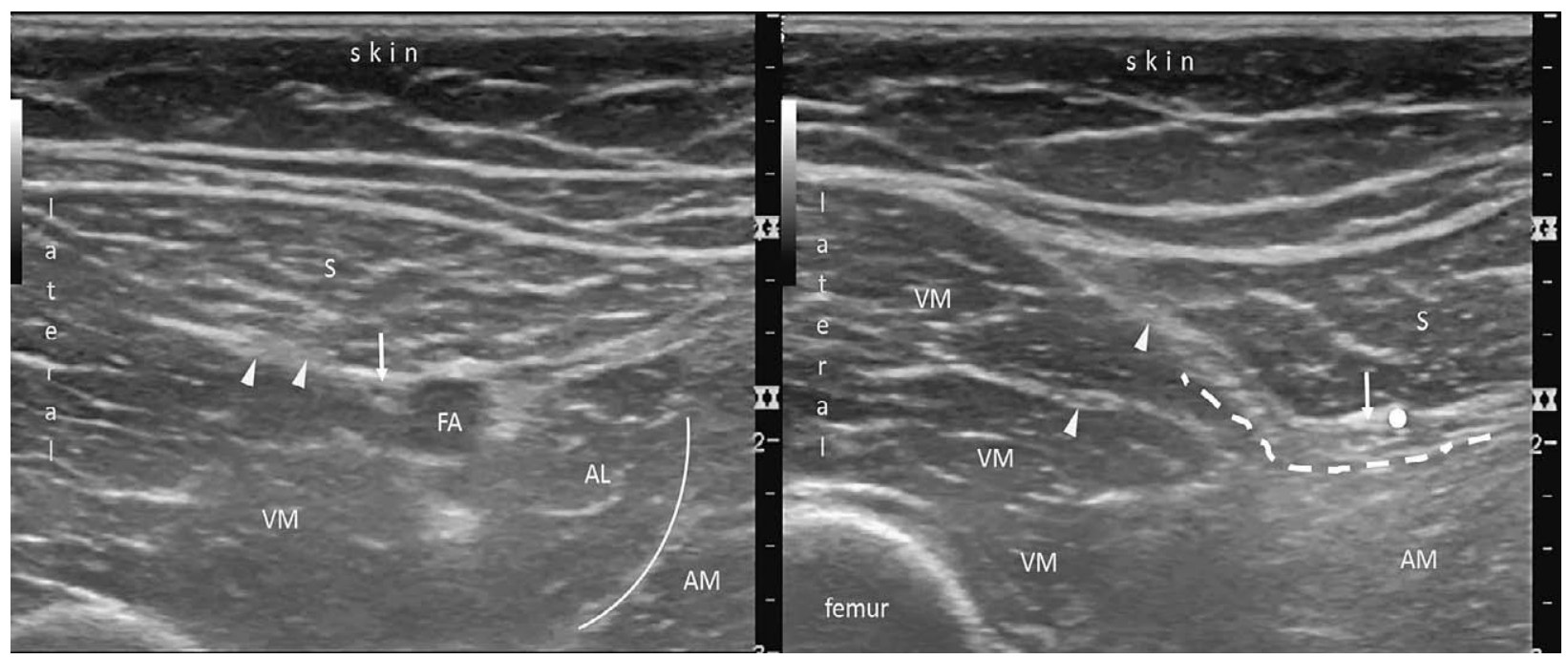

Figure 2. Appex of femoral triangle (A) and distal adductor canal (B).

Arrow - saphenous nerve; arrow heads - branches to vastus medialis; solid dot - descending genicular artery; dotted line - vastoadductor membrane; solid curve - medial border of AL; VM- vastus medialis muscle; AL - adductor longus muscle; AM - adductor magnus muscle; $\mathrm{S}$ - sartorious muscle 


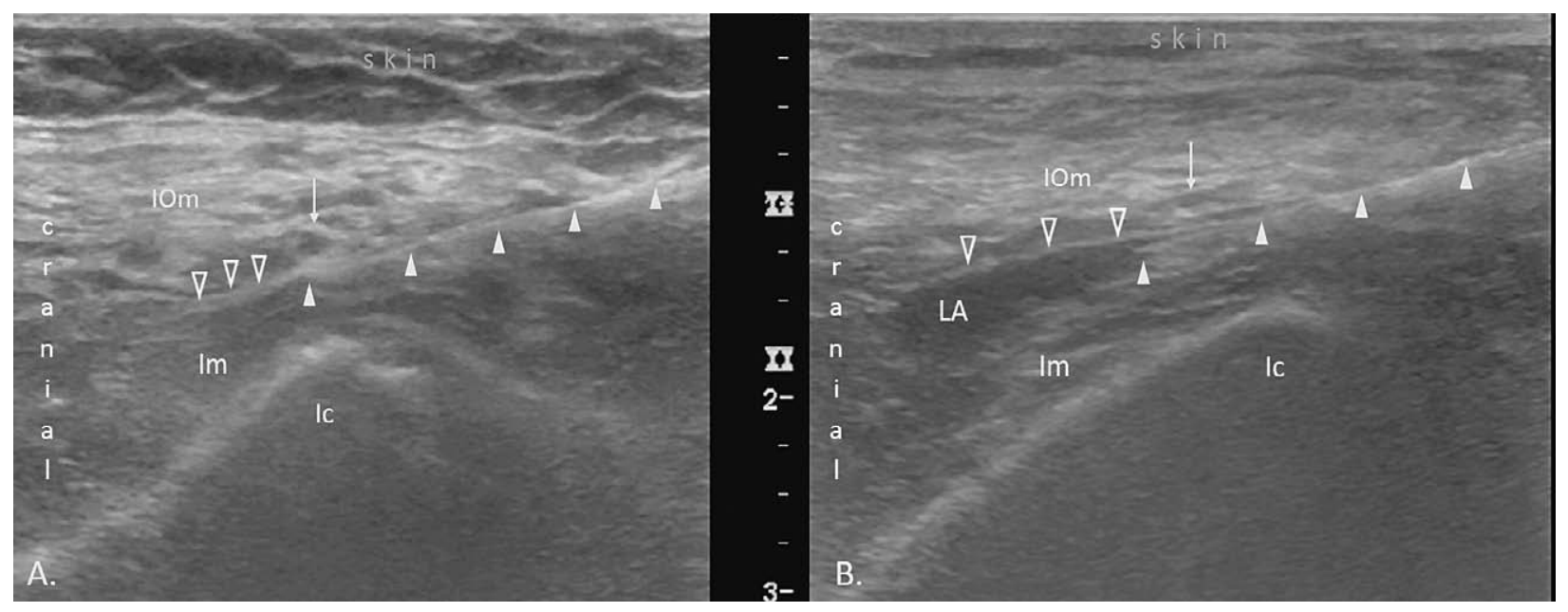

Figure 3. Longitudinal suprainguinal fascia iliaca block.

Ic - illiac crest; Im - illiac muscle; IOm- internal oblique muscle; arrow - deep circumflex artery; empty arrowheads - illiac fascia; arrowheads - needle; LA - local anesthetic

and knee. Quadriceps muscle weakness due to femoral nerve block impairs gait control and weight bearing, thus increasing risk of falls and being a major disadvantage of the classic proximal approach.

In an attempt to minimize muscle strength impairment, techniques targeting mainly the saphenous nerve, the major sensory branch of the femoral nerve, more distally in the femoral triangle have been described.

\section{Subsartorial femoral triangle block}

In the mid-thigh region, at the mid point in between the anterior superior iliac spine and base of patella, the saphenous nerve lies adjacent and anterolateral to the femoral artery in between the sartorious and medial vastus muscle (fig. 2A). By performing the block at this level besides the saphenous nerve the branch to the medial vastus muscle and the medial femoral cutaneous nerve, all contributing to the patellar plexus, are also blocked ${ }^{4}$. The needle is inserted in plane in an anterolateral to posteromedial direction.

\section{Adductor canal block}

The adductor canal is continuous with the apex of the femoral triangle and begins at the intersection of the medial margins of the sartorious and adductor longus muscles where the vastoadductor membrane be- gins and forms its roof. The saphenous nerve is the only one consistently entering the proximal part of the adductor canal. It then pierces the vastoadductor membrane and exits the adductor canal to run more superficial next to the descending genicular artery (fig. 2B). Performing a block in the distal part of the adductor canal may spare the saphenous nerve, but has been shown to result in local anesthetic spread to the popliteal fossa and block of the popliteal nerve plexus formed by genicular branches of the posterior obturator and tibial nerves contributing to the innervation of the posterior knee region 5 .

\section{Longitudinal suprainguinal fascia iliaca block}

In an attempt to block all three major branches of the lumbar plexus with a single injection of local anesthetic, the fascia iliaca block was introduced. Originally the injection was made $2 \mathrm{~cm}$ distal to a point in between the middle and lateral thirds of an imaginary line joining the anterior superior iliac spine and the pubic tubercle, i.e. it was performed on the anterior thigh distal to the inguinal ligament. It is a "double click“ or "double pop" loss of resistance technique based on the sensation of piercing the fascia lata and then the iliac fascia with the needle and then injecting a large volume of local anesthetic. The goal was to reach the lateral femoral cutaneous, the femoral an obturator nerves. In clinical practice this approach often 


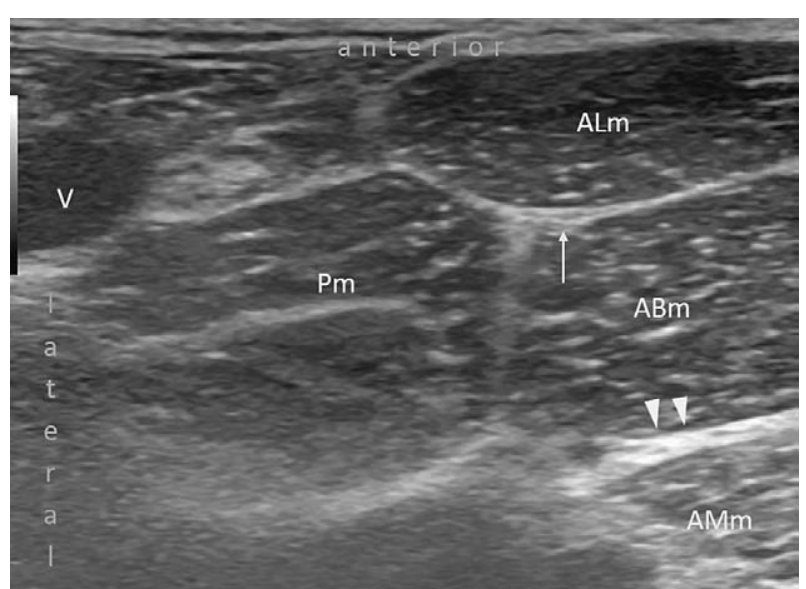

Figure 4. Obturator nerve branches. Arrow - obturator nerve superficial branch; arrowheads - obturator nerve deep branch.

ALm - adductor longus muscle; $\mathrm{ABm}$ - adductor brevis muscle; $\mathrm{AMm}$ - adductor magnus muscle; $\mathrm{V}$ - femoral vein

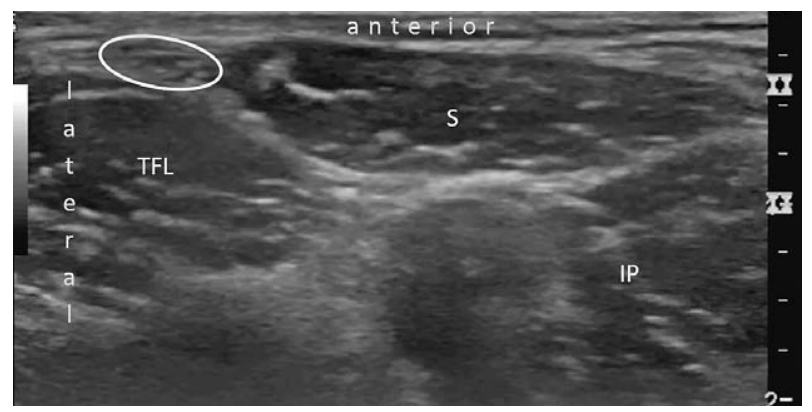

Figure 5. Lateral femoral cutaneous nerve.

$\mathrm{S}$ - sartorious muscle; TFL - tensor fasciae latae muscle; IP - Ileopsoas muscle; oval - lateral femoral cutaneous nerve

failed to provide the expected level of analgesia even when performed under ultrasound guidance ${ }^{6}$. In an attempt to achieve a more consistent spread of local anesthetic to all three nerves, a technique was described in which the injection is made cranial to the inguinal ligament medial to the anterior superior iliac spine ${ }^{7}$. With the ultrasound probe in an oblique sagittal direction, the iliac fascia, internal oblique, sartorious and iliac muscles are identified and the needle introduced in plane bellow the inguinal fascia which is then hydrodisected by local anesthetic injection from the iliac muscle (fig. 3). The deep circumflex artery can usually be identified and lies superficial to the fascia. Upward movement (towards the probe) of the artery during local anesthetic injection can be used as a marker of correct injection plane.

\section{Obturator nerve block}

The obturator nerve arises from the L2-L4 roots of the lumbar plexus and after emerging from the psoas muscle it runs downward through the obturator foramen. As it leaves the pelvis it divides into two branches. The anterior branch can be found in between the adductor longus muscle anteriorly and the adductor brevis and magnus muscles posteriorly while the posterior branch of the obturator nerves runs beneath the adductor brevis and on top of the adductor magnus muscle. To visualize the branches at this point, the ultrasound probe is positioned on the medial thigh with the leg rotated outward. The aim is to visualize the pectineus laterally and adductor muscles medially (fig. 4). When performing an in plane approach from lateral to medial, it is important to visualize the femoral vessels that lie laterally and avoid them in the needle path. The objective is to obtain an interfascial local anesthetic spread between the adductor longus and brevis muscles and between the adductor brevis and magnus muscles. Injecting the local anesthetic in between the pectineus and adductor brevis muscle usually also results in an anterior branch block ${ }^{8}$.

\section{Lateral femoral cutaneous nerve}

The lateral femoral cutaneous nerve arises from the dorsal divisions of the L2-L3 lumbar plexus roots. After emerging from the lateral border of the psoas major muscle, it runs laterally towards the anterior superior iliac spine. It then passes under the inguinal ligament and over the sartorius muscle into the thigh providing sensory innervation to the lateral and anterior thigh. The nerve usually has a highly variable course and sometimes branches before crossing the inguinal ligament, passing at varying distances from the anterior superior iliac spine. Ultrasound can be used to identify the interfascial plane between the sartorius and tensor fasciae latae muscles in which the nerve (branches) lie and a reliable block of the lateral femoral cutaneous nerve can be achieved by injecting local anesthetic into this space (fig. 5). The probe position is just medial and a little distal from the anterior superior iliac spine.

\section{Sciatic nerve blocks}

The sciatic nerve is formed by branches of both anterior and posterior divisions of the lumbosacral plexus 


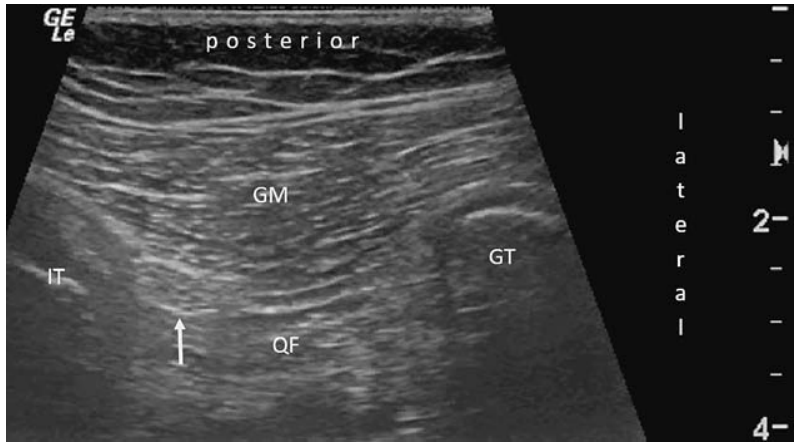

Figure 6. Sciatic nerve-proximal.

Arrow - sciatic nerve; GM - glureus maximus muscle; QF - quadratus femoris muscle; GT - greater trochanter; IT - ischial tuberosity

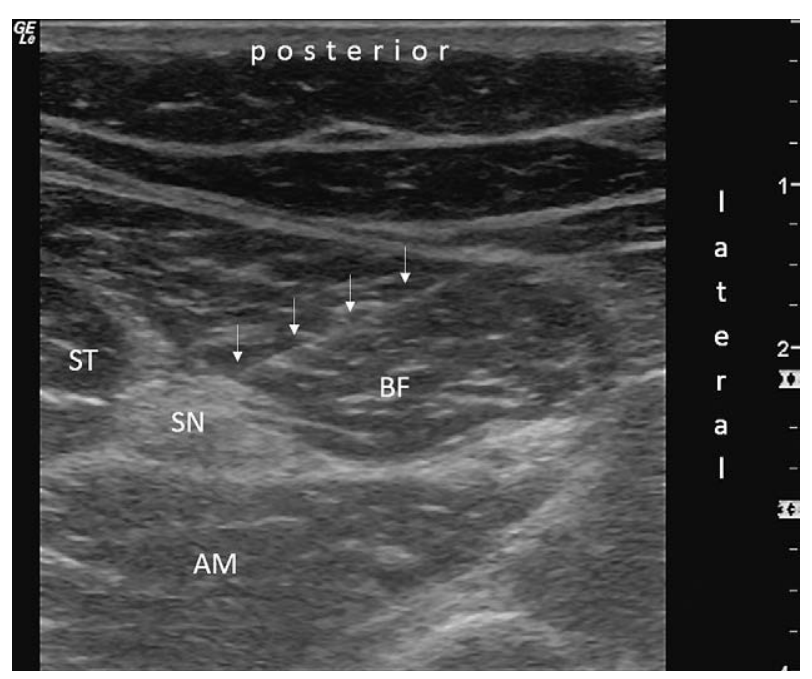

Figure 7. Subgluteal sciatic nerve block.

ST - semitendinosus muscle; BF - biceps femoris muscle; AM adductor magnus muscle; $\mathrm{SN}$ - sciatic nerve; arrows -26 gauge needle

(L4-S3) and innervates the posterior thigh and almost the entire lower leg. Due to its deep location it is a technically demanding block when performed in the parasacral and gluteal region' (fig. 6), however it is readily visible with ultrasound from the subgluteal to popliteal region. After emerging into the posterior thigh below the gluteus muscle it can be found in between the semitendinosus muscle medially, the long head of biceps femoris muscle laterally and posterior to the adductor magnus muscle. Putting the ultrasound probe on the posterior aspect of the proximal thigh the fascial planes between the muscles roughly form a "mercedes" sign with the sciatic nerve at the

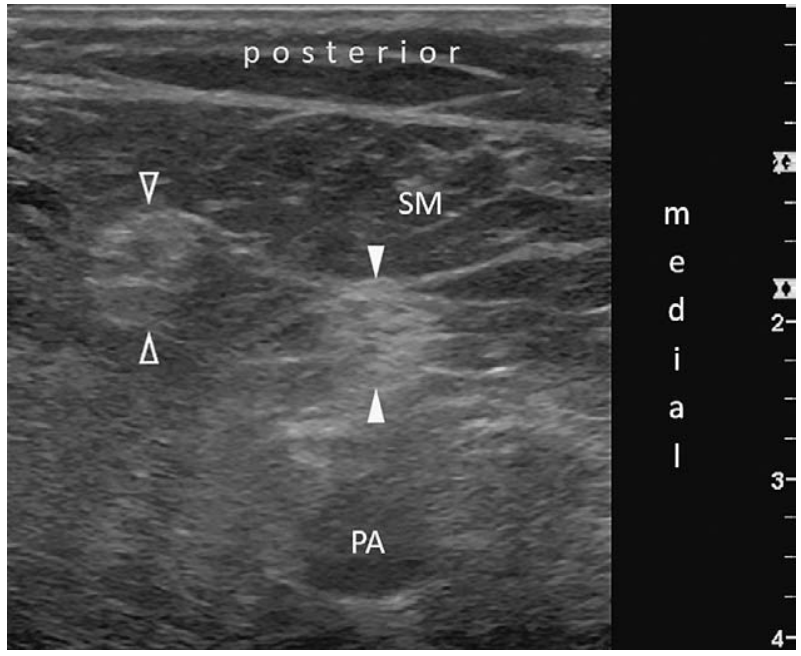

Figure 8. Sciatic nerve division in popliteal fossa.

PA - popliteal artery; SM - semimembranosus muscle; solid arrowheads - tibial nerve; arrowheads outline - common peroneal nerve

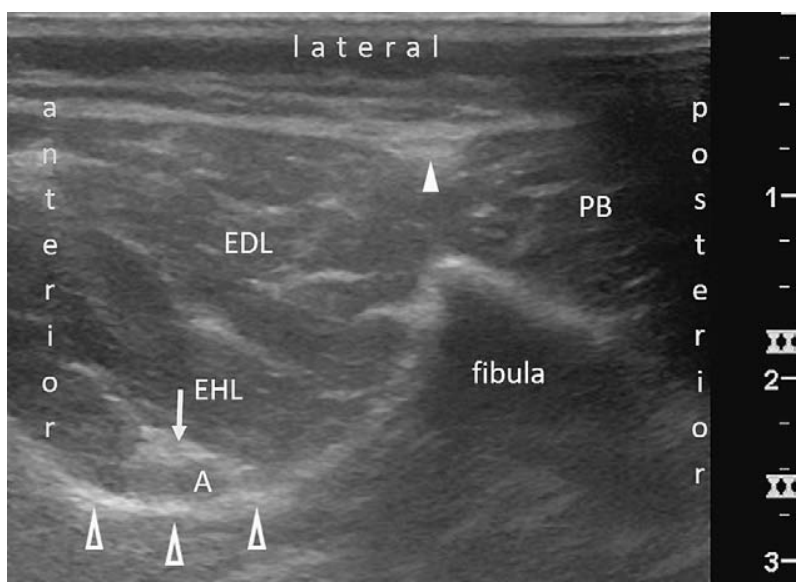

Figure 9. Superficial and deep peroneal nerves.

$\mathrm{PB}$ - peroneus brevis muscle; EDL - extensor digitorum longus muscle; EHL - extensor hallucis longus muscle; A - anterior tibial artery; solid arrowhead - superficial peroneal nerve; arrow - deep peroneal nerve; arrowhead outline - interosseous membrane

middle (fig. 7). As it reaches the popliteal fossa the nerve divides (fig. 8) into the tibial nerve which continues into the posterior compartment of the foot and the common peroneal nerve which runs laterally and after crossing the fibular head, it divides into a deep and superficial branch which enter the anterior and lateral compartments of the foot (fig 9).

Proximal blocks of the sciatic nerve are used to supplement lumbar plexus and femoral nerve blocks 
for surgeries performed on the thigh and knee, while blocking it at the popliteal region produces excellent anesthesia for most below the knee surgical procedures

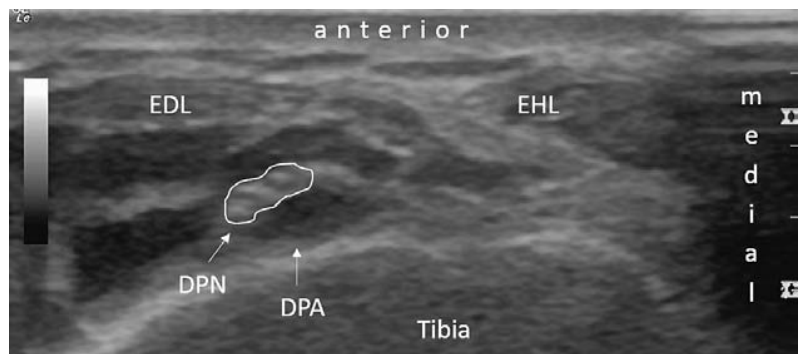

Figure 10. Deep peroneal nerve at the ankle.

DPN - deep peroneal nerve; DPA- dorsalis pedis artery; EDL extensor digitorum longus tendon; EHL - extensor hallucis longus tendon with the advantage of preserving hamstrings muscle strength and knee flexion. Sometimes a saphenous nerve block is added to improve calf tourniquet tolerance and provide complete anesthesia for surgeries involving the anteromedial portion of the lower leg.

\section{Distal blocks}

For surgeries involving the foot, individual terminal branches of the sciatic and femoral nerves can be targeted at the mid and distal third of the foot to avoid motor block at the level of the ankle. The superficial branch of the common peroneal nerve runs through a fascial compartment between the extensor digitorum longus and peroneus brevis muscles to reach a superfi-

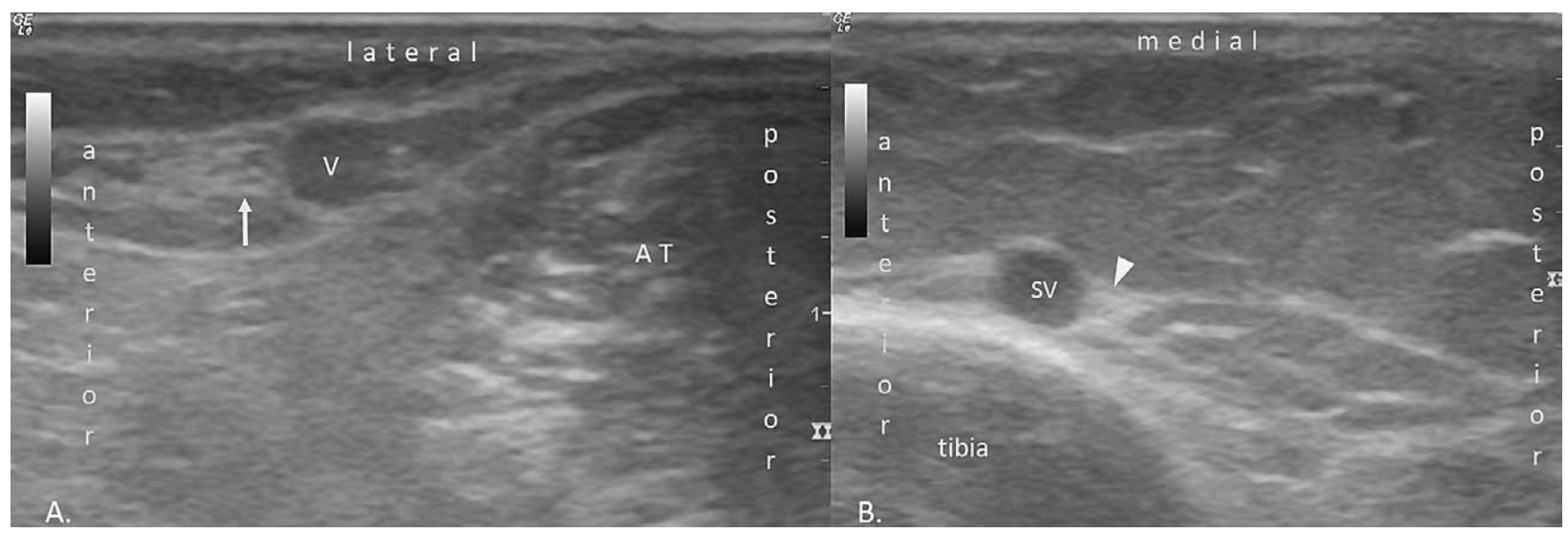

Figure 11. Supramalleolar view of sural $(A)$ and saphenous $(B)$ nerve.

Arrow - sural nerve; V - lesser saphenous vein; AT - Achilles tendon; SV - great saphenous vein; arrowhead - saphenous nerve

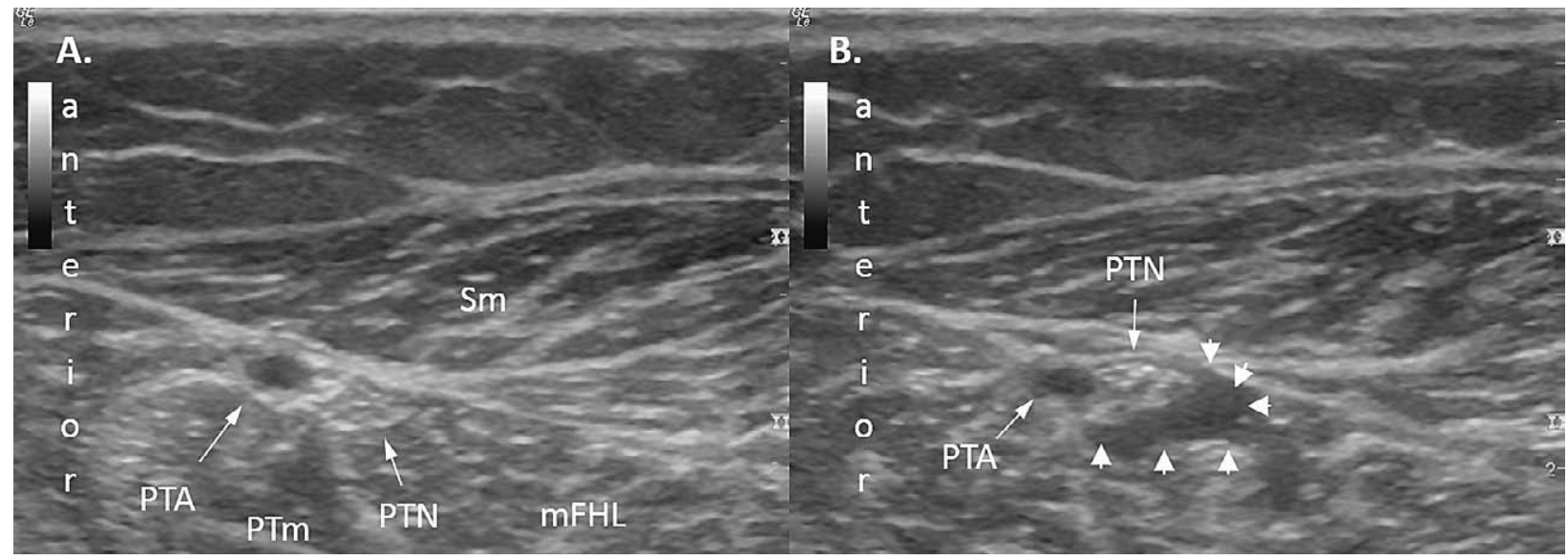

Figure 12. A. Tibial nerve and artery in the supramaleolar region B. Spread of local anesthetic (arrowheads).

PTA - posterior tibial artery; PTN - posterior tibial nerve; PTm - posterior tibial muscle;mFHL - flexor hallucis longus muscle; Sm soleus muscle 
cial subcutaneous position at the mid third of the lower leg (fig. 9) This is the level at which it should be blocked if its entire sensory distribution to the dorsum of the foot wants to be covered since soon after reaching a subcutaneous position it divides into a medial and lateral terminal branch which diverge from each other and one of them may remain unaffected if the block is performed at a more distal location. The deep peroneal nerve provides sensory innervation to the first interdigital webspace and can be selectively blocked at the level of the ankle where it is intimately related to the dorsalis pedis artery (fig. 10) The sural nerve is a sensory nerve which receives contributions from both the tibial and common peroneal nerves and supplies sensation to the skin of the lateral foot and ankle. Once formed it runs distally in a superficial plane along the lesser (small) saphenous vein. The nerve can be easily identified by ultrasound beside the vein (fig. 11A) before it passes behind the lateral malleolus. To enhance visibility of the vein and prevent it from collapsing under the pressure of the ultrasound probe a tourniquet can be placed proximally prior to block performance. In a similar manner the saphenous nerve can be blocked at the medial aspect of the lower leg where it runs along the greater saphenous vein (fig. 11B). The saphenous nerve provides sensation to the skin of the medial ankle and contributes to sensation of the medial side of the foot, variably as far as the ball of the great toe.

In the lower leg the tibial nerve travels posteriorly between the superficial and deep muscle group and along the posterior tibial artery. It passes posterior to the medial malleolus where it divides into a medial calcaneal branch and medial and lateral plantar branches. It provides sensory innervation to most of the plantar surface of the foot and the medial aspect of the heel. Using ultrasound the tibial nerve is identified at the medial aspect of the ankle posterolateral to the posterior tibial artery (fig. 12). By asking the patient to flex the toes, it can be distinguished from the also hyperechoic flexor tendons.

In conclusion, by combining ultrasound guidance with a detailed knowledge of the underlying anatomy, we can provide effective regional anesthesia tailored to the individual needs of the patient, avoiding motor block when early mobilization is required, without compromising analgesia and decreasing procedure associated time and risks.

\section{References}

1. Neal JM, Brull R, Horn JL et al. The Second American Society of Regional Anesthesia and Pain Medicine Evidence-Based Medicine Assessment of Ultrasound-Guided Regional Anesthesia: Executive Summary. Reg Anesth Pain Med 2016;2: 181-94.doi: 10.1097/AAP.0000000000000331.

2. Marhofer P, Harrop-Griffiths W, Kettner SC, Kirchmair L. Fifteen years of ultrasound guidance in regional anaesthesia: Part 1. Br J Anaesth 2010;104:538-46.doi: 10.1093/bja/aeq069.

3. Wong WY, Bjørn S, Strid JM, Børglum J, Bendtsen TF. Defining the Location of the Adductor Canal Using Ultrasound. Reg Anesth Pain Med 2017;42:241-5. doi: 10.1097/AAP.0000000000000539.

4. Bendtsen TF, Moriggl B, Chan V, Børglum J. The optimal analgesic block for total knee arthroplasty. Reg Anesth Pain Med. 2016;41:711-19. doi: 10.1097/AAP.0000000000000485

5. Runge C, Moriggl B, Børglum J, et al. The Spread of Ultrasound-Guided Injectate From the Adductor Canal to the Genicular Branch of the Posterior Obturator Nerve and the Popliteal Plexus: A Cadaveric Study. 2017;42:725-30. doi: 10.1097/AAP.0000000000000675.

6. Shariat AN, Hadzic A, XuD, et al. Fascia lliaca block for analgesia after hip arthroplasty: a randomized double-blind, placebo-controlled trial. Reg Anesth Pain Med. 2013;38:201-5. doi: 10.1097/AAP.0b013e31828a3c7c.

7. Desmet M, Vermeylen K, Van Herreweghe I et al. A Longitudinal Supra-Inguinal Fascia Iliaca Compartment Block Reduces Morphine Consumption After Total Hip Arthroplasty. Reg Anesth Pain Med 2017;42:327-33. doi: 10.1097/AAP.0000000000000543.

8. Sinha SK, Abrams JH, Houle TT, et al. Ultrasound-guided obturator nerve block: an interfascial injection approach without nerve stimulation. Reg Anesth Pain Med. 2009; 34(3): 261-4. doi: 10.1097/AAP.0b013e3181a32c4d.

9. Abdallah FW, Chan VW. Proximal Sciatic Nerve Block-Ultrasound Guided. In: Jankovic D, Peng P, editors. Regional Nerve Blocks in Anesthesia and Pain Therapy. Springer, Cham; 2005. p.801-9.https://doi.org/10.1007/978-3-319-05131-4_60 
Sažetak

\title{
ULTRAZVUK U REGIONALNOJ ANESTEZIJI DONJIH EKSTREMITETA - BLOKOVI ŽIVACA I VIŠE
}

\author{
K. Oremuš
}

Tijekom proteklih deset godina ultrazvukom vođene tehnike postale su zlatni standard u izvođenju blokova perifernih živaca. Upotreba ultrazvuka skratila je vrijeme izvođenja blokova, omogućila smanjenje ukupnog volumena lokalnog anestetika potrebnog za uspješan blok kao i rizik nehotične intravaskularne injekcije te potrebu za dodatnom opioidnom analgezijom u odnosu na tehnike zasnovane na orijentaciji prema odrednicama površinske anatomije pacijenta i vođene neurostimulacijom. Korištenje ultrazvuka ne smije se shvatiti kao nadomjestak, već bi trebalo biti nadopuna temeljitom poznavanju anatomije. Svrha ovoga pregleda je predočiti ultrazvukom vođene tehnike pri izvođenju osnovnih blokova donjeg ekstremiteta kao i raspraviti novije trendove u regioanlnoj analgeziji pacijenata podvrgnutih operacijama donjeg ekstremiteta.

Ključne riječi: regionalna anestezija, ultrazvuk, donji ekstremiteti 